\title{
Plastic antibody for DNA damage: fluorescent imaging of BPDE-dG adducts in genomic DNA $\uparrow$
}

\begin{abstract}
Junfa Yin, Zhixin Wang, Maoyong Song, Chao Zhao and Hailin Wang*
Exogenous and endogenous genotoxic carcinogens and their in vivo metabolites may result in DNA damage and cause adverse health effects. It is very difficult to specifically detect trace DNA damage in the presence of a large excess of unmodified nucleosides. Here we report a molecularly imprinted polymer (MIP) nanocomposite, namely nanoMIP, which can be used as a "plastic antibody" for specific recognition of benzo[a]pyrene diol epoxide (BPDE)-DNA adduct. Enhanced binding affinity (880 nM) of nanoMIPs was achieved by using two tailor-made functional monomers. The property of binding kinetics was greatly improved in virtue of the well-defined nanostructure, which was fabricated by initiators for continuous activator regeneration-atom transfer radical polymerization (ICAR-ATRP). The BPDE-adducted DNA can be specifically captured by synthetic nanoMIP. By taking advantage of this antibody-mimicking behavior, we further developed a fluorescently imaged particle counting immunoassay (FIPCIA) method for ultrasensitive detection of BPDE-ssDNA adducts using a laser scanning confocal microscope (LSCM). The number of countable fluorescent dots is proportional to the content of BPDE-ssDNA adducts in the DNA sample. The proposed plastic antibody-based FIPCIA method can detect traces of BPDE-DNA adducts as low as 18 pM in human lung carcinoma A549 cells. This highly-sensitive detection of DNA lesions offers a promising alternative to immunogenic antibodybased immunoassays for genomics and DNA modification analysis.
\end{abstract}

Received 7th March 2013

Accepted 20th May 2013

DOI: 10.1039/c3an00467h

www.rsc.org/analyst generally involves two approaches: phage display and systematic evolution of ligands by exponential enrichment (SELEX). These biological approaches are somewhat time-consuming, and many technical difficulties have been encountered during the course of peptide and aptamer creation. So far only a small number of peptides and aptamers for DNA damage have been obtained from these approaches, including two peptides for $O^{6}$-methyldeoxyguanosine and thymidine $(6,4)$ thymidine photoproducts created by phage display, ${ }^{17,18}$ and no more than ten aptamers for 7-methyl-guanosine and 8-hydroxy-2'-deoxyguanosine (8-OHdG) evolved by SELEX. ${ }^{19-21}$

The chemistry-based molecular imprinting technique may be a better choice to fabricate artificial antibodies, and it is currently a promising tool for the creation of antibody-mimicking polymers, namely molecularly imprinted polymers (MIPs), due to their remarkable specificity and chemical robustness. ${ }^{22-28}$ MIPs for 8-OHdG, a biomarker for DNA oxidative damage, have been prepared and applied in highly-sensitive biosensing of nanomolar 8-OHdG in human blood and urine samples..$^{29,30}$

A challenge in exploring MIPs as artificial antibodies is to attain higher affinity, which needs to be sufficient for specific binding of targets from an excess of complex matrix. MIPs usually possess affinities (represented by the equilibrium dissociation constant $K_{\mathrm{D}}$ ) from several millimolar to tens of micromolar towards the imprinted molecule, which is nearly 1000 -fold lower than that of natural antibodies $\left(K_{\mathrm{D}} \sim 10^{-9} \mathrm{M}\right)$. 
In recent years, much effort has been devoted to produce more potent MIPs with affinities as high as sub-micromolar (even nanomolar). Designing new functional monomers and tuning compositions of the prepolymerization system are often involved in the literature. ${ }^{30}$ Meanwhile, modulating the forms and sizes of MIPs and utilizing novel polymerization techniques are also expected to enhance the binding affinity. MIP nanomaterials have been prepared and showed nanomolar affinity towards their targets. ${ }^{31,32}$ They may have many advantages over the traditional MIP particles, including homogenous binding site distribution, a high yield of high-affinity sites and good site accessibility. ${ }^{\mathbf{2 4 3 1 - 3 3}}$

Atom transfer radical polymerization (ATRP), a novel living/ controlled radical polymerization technique, has been successfully used for the fabrication of nanoscaled MIPs with ordered structures and improved binding properties. ${ }^{33,35,36}$ ATRP allows polymers to be grown in a controlled, piece-by-piece fashion, and enables researchers to create a wide range of polymers with site specific tailored functionalities for various applications..$^{34-37}$

The aim of this study is to fabricate a high-affinity plastic antibody for benzo[a]pyrene diol epoxide (BPDE)-DNA adducts, a DNA damage product produced by benzo $[a]$ pyrene $(\mathrm{B}[a] \mathrm{P})$ exposure, using an initiator for continuous activator regeneration-atom transfer radical polymerization (ICAR-ATRP). $\mathrm{B}[a] \mathrm{P}$ is a carcinogenic polycyclic aromatic hydrocarbon that can be metabolized in vivo into a reactive metabolite BPDE. The latter can further covalently bind to deoxyguanosine (dG) in DNA and preferentially form BPDE-DNA adducts at lung cancer mutational hotspots in tumor suppressor gene p53.,40 In our previous work, we developed a fluorescently imaged particle counting immunoassay (FIPCIA) method for rapid and sensitive detection of BPDE-DNA adducts in cultured cancer cells. ${ }^{41}$ In that case, the BPDE-adducted DNA was captured by natural antibody conjugated magnetic particles, followed by OliGreen dye staining and particle counting from LSCM fluorescence imaging. Here we report an artificial antibody, namely nanoMIP, fabricated with ssDNA adduct probe as the template, which is capable of specific recognition of the BPDE-DNA adduct. The sub-micromolar affinity was achieved by using two tailor-made new functional monomers. The homogeneity of binding sites and the mass transfer were greatly improved in virtue of the well-defined nanostructure, which was constructed by ICAR-ATRP (Scheme 1). ${ }^{35,42-44}$ We further demonstrated that this nanoMIP could be applied as a plastic antibody for direct fluorescent imaging of BPDE-SSDNA adducts in genomic DNA isolated from cultured cancer cells.

\section{Experimental}

\subsection{Chemicals and reagents}

Anti-benzo(a)pyrene-trans-7,8-dihydrodiol-9,10-epoxide (antiBPDE) was supplied by National Cancer Institute Chemical Carcinogen Reference Standard Repository (Kansas, MO, USA). $p$-Tert-butylcalix $[n]$ arenes were purchased from TCI (Tokyo, Japan). Allyl bromide, ethylene dimethacrylate (EDMA), methacrylic acid (MAA) and 4-vinylpyridine (4-VP) were from Acros (NJ, USA). Copper(I) bromide (CuBr), $N, N, N^{\prime}, N^{\prime \prime}, N^{\prime \prime}$-pentamethyldiethylenetriamine (PMDETA), tris[2-(dimethylamino)ethyl]-

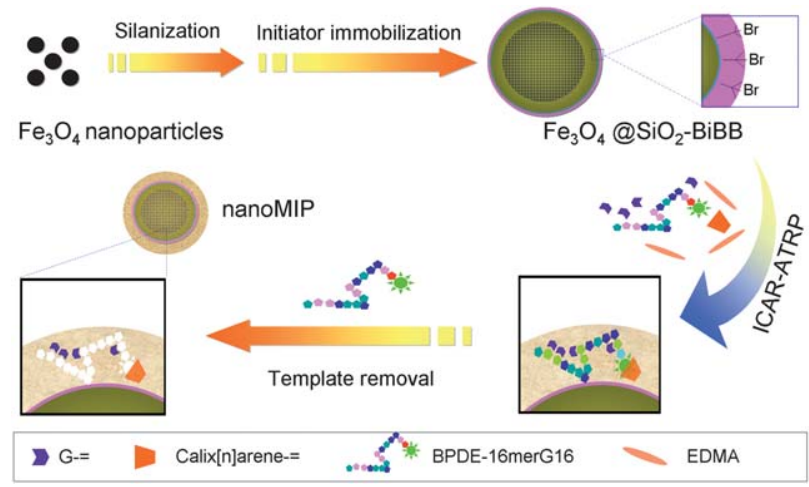

Scheme 1 Fabrication of core-shell nanoMIP for BPDE-16merG16 adduct by an ICAR-ATRP strategy. $\mathrm{Fe}_{3} \mathrm{O}_{4}$ nanoparticles were first silanized with 3-aminopropyltriethoxysilane (APTES), and modified with the initiator (2-bromoisobutyryl bromide, BiBB). Then, the MIP precursor consisted of DNA template, functional monomers, crosslinker, catalyst and initiator triggered ICAR-ATRP reaction. After the template removal, nanoMIP could be further used in DNA adduct capture and detection.

amine ( $\left.\mathrm{Me}_{6} \mathrm{TREN}\right)$, 2-bromoisobutyryl bromide (BiBB), tetraethyl orthosilicate (TEOS), 3-aminopropyltriethoxysilane (APTES), $N, N$-diisopropylethylamine, $N, N$-dimethylacetamide, diphenylcarbamoyl chloride and mercuric acetate $\left((\mathrm{AcO})_{2} \mathrm{Hg}\right)$ were from Sigma-Aldrich (MO, USA). Span 80 (viscosity 1200$2000 \mathrm{mPa} \mathrm{s}$ ) was from Fluka. Fluorescent dye OliGreen (for ssDNA staining) was from Invitrogen (Carlsbad, CA, USA). Other chemicals of analytical grade were supplied by SigmaAldrich (MO, USA). Deionized water (resistivity $18.2 \mathrm{M} \Omega \mathrm{cm}$ ) was prepared from an ELGA system (Elga, UK).

The ssDNA and the 5 -fluorescein labeled ssDNA probes, including 16merG16 (TCCATTATCCATAACg), 16merG9 (TCCATTATgCATAACC), 22merG22 (CCCATTCCCATCA TCCA CAACg), 16merG16-FAM (5'-FAM-TCCATTATCCATAACg) and 16merG9-FAM (5'-FAM-TCCATTATgCATAACC), were purchased from Sangon Biotech (Shanghai, China). The guanine position in each strand was further modified with anti-BPDE to produce each BPDE-SSDNA adduct probe (Scheme 2) according to our previous work. ${ }^{41,45}$

\subsection{Synthesis of allyl-armed calix $[n]$ arene monomers}

Allylated calix $[n]$ arene monomers (calix $[n]$ arene- $=$ ) were synthesized according to the previous literature with a little

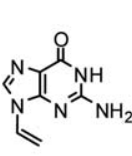

$1, \mathrm{G}=$

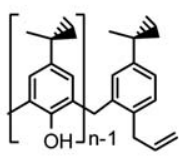

Calix[n]arene-
2, $n=4$

3, $\mathrm{n}=6$

4, $n=8$

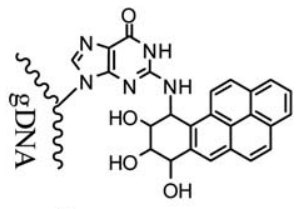

5, BPDE-gDNA adduct
6, BPDE-16merG16: TCCATTATCCATAACg(BPDE)

7, BPDE-16merG9: TCCATTATg(BPDE)CATAACC

8, BPDE-22merG22: CCCATTCCCATCATCCACAACg(BPDE)

Scheme 2 The functional monomers and BPDE-DNA adduct probes used in ATRP synthesis of nanoMIP. 
modification. ${ }^{\mathbf{4 6 , 4 7}}$ Firstly, a suspension of $\mathrm{K}_{2} \mathrm{CO}_{3}(0.03 \mathrm{~g}$, $0.2 \mathrm{mmol})$ and $p$-tert-butylcalix $[n]$ arene $(0.2 \mathrm{mmol})$ in acetonitrile $(10 \mathrm{~mL})$ was stirred at $65{ }^{\circ} \mathrm{C}$ for $1 \mathrm{~h}$. Then $2.0 \mathrm{mmol}$ of 3-bromopropene was added into this mixture and continuously stirred for $36 \mathrm{~h}$. The solvent was removed under reduced pressure, and the solid residue was taken up in $\mathrm{CH}_{2} \mathrm{Cl}_{2}(50 \mathrm{~mL})$, then washed with $1 \mathrm{M} \mathrm{HCl}$ twice. The $\mathrm{CH}_{2} \mathrm{Cl}_{2}$ layer was dried with the anhydrous $\mathrm{MgSO}_{4}(5 \mathrm{~g})$ overnight, filtered and evaporated to give an off-white crude product. The crude product was refined by an ethyl acetate extraction, by which the unsubstitutedcalix$[n]$ arenes were removed.

The total yields were $31.1 \%$ for the monoallylated $p$-tertbutylcalix[4]arene (2), 17.5\% for the allylated $p$-tert-butylcalix[6]arene (3) and $11.2 \%$ for the allylated $p$-tert-butylcalix[8]arene (4), respectively. For the allylated $p$-tert-butylcalix[6]arene $(3),{ }^{1} \mathrm{H}$ NMR $(\delta, \mathrm{ppm})\left(\mathrm{CDCl}_{3}\right): 1.05(\mathrm{~s}, 9 \mathrm{H}), 1.15(\mathrm{~s}, 9 \mathrm{H}), 1.21(\mathrm{~s}, 18 \mathrm{H})$, 1.25 (s, 18H), 3.40-3.90 (m, 12H), 5.31 (d, 1H, $J=9.2 \mathrm{~Hz}), 5.90$ (d, $1 \mathrm{H}, J=16.2 \mathrm{~Hz}), 6.18(\mathrm{~m}, 1 \mathrm{H}), 6.95-7.16(4 \mathrm{~s}, 12 \mathrm{H}), 7.94(\mathrm{~s}, 2 \mathrm{H})$, 8.43 (br s, 1H), 8.81 (br s, 2H); FT-IR $\left(\nu_{\max }, \mathrm{cm}^{-1}\right)$ (KBr): 3355, 3049, 2964, 1642, 1485, 1363, 1205; MS (+): $m / z[\mathrm{M}+\mathrm{H}]^{+} 1014.67$.

\subsection{Synthesis of guanine-based monomer $(\mathrm{G}-=)$}

Guanine $(5.0 \mathrm{~g}, 33.1 \mathrm{mmol})$ and acetic anhydride $(10 \mathrm{~mL}$, $106 \mathrm{mmol})$ were refluxed in dry $N, N$-dimethylacetamide $(50 \mathrm{~mL})$ for $6 \mathrm{~h}$ under nitrogen protection. The solid product $(5.7 \mathrm{~g})$ was collected and suspended in a mixture of dry pyridine $(92 \mathrm{~mL})$ and $N, N$-diisopropylethylamine $(8 \mathrm{~mL})$. To this suspension, diphenylcarbamoyl chloride $(6.0 \mathrm{~g}, 25.9 \mathrm{mmol})$ was added and the mixture was stirred for $4 \mathrm{~h}$ under a nitrogen atmosphere. After that, $10 \mathrm{~mL} \mathrm{H}_{2} \mathrm{O}$ was injected and the reaction continued for $15 \mathrm{~min}$. Solvents were removed by vacuum distillation and residues were suspended in a mixture of ethanol $(15 \mathrm{~mL})$ and $\mathrm{H}_{2} \mathrm{O}(15 \mathrm{~mL})$, then refluxed for $3 \mathrm{~h}$. When the reaction was complete, the suspension was cooled and filtered, and a white solid 9 was obtained $(10.4 \mathrm{~g}, 82 \%) .5 .0 \mathrm{~g} \mathrm{Hg}(\mathrm{OAc})_{2}$ was dissolved in a mixture of vinyl acetate $(50 \mathrm{~mL})$, ethyl acetoacetate $(15 \mathrm{~mL})$ and acetic acid $(1.2 \mathrm{~mL})$. To this solution, compound $9(6.0 \mathrm{~g}$, $15 \mathrm{mmol})$ and hydroquinone $(0.1 \mathrm{~g})$ in DMF $(75 \mathrm{~mL})$ was added. The mixture was refluxed overnight. Precipitates were formed when $\mathrm{Na}_{2} \mathrm{CO}_{3}$ aqueous solution $(0.1 \mathrm{M})$ was added, and were filtered off. The filtrate was extracted with diethyl ether $(50 \mathrm{~mL} \times$ 3 ). Then diethyl ether was removed by distillation, and a lightyellowish solid 10 was obtained (3.15 g, 51\%). The product 10 was then hydrolyzed by ammonia $(17 \%)$ in ethanol $(100 \mathrm{~mL})$ for $8 \mathrm{~h}$, and the allylated guanine (1) was obtained as the final product.

Yield (total): $36 \%, \mathrm{mp}:>290{ }^{\circ} \mathrm{C}$. FT-IR $\left(\nu_{\max }, \mathrm{cm}^{-1}\right)(\mathrm{KBr})$ : 3321, 3174, 1692, 997, 890. ${ }^{1} \mathrm{H}$ NMR $\left(\delta\right.$, ppm) $\left(\right.$ DMSO-d $\left._{6}\right): 5.10$ $(\mathrm{d}, 1 \mathrm{H} ; J=9.2 \mathrm{~Hz}), 5.68(\mathrm{~d}, 1 \mathrm{H}, J=16.2 \mathrm{~Hz}), 6.68(\mathrm{br} \mathrm{s}, 2 \mathrm{H}), 7.18$ (dd, $1 \mathrm{H}, J_{1}=16.2 \mathrm{~Hz}, J_{2}=9.2 \mathrm{~Hz}$ ), $8.05(\mathrm{~s}, 1 \mathrm{H}), 9.51$ (br s, $1 \mathrm{H}$ ). MS (+): $m / z[\mathrm{M}+\mathrm{H}]^{+}$178.214. Anal. calcd for $\mathrm{C}_{7} \mathrm{H}_{7} \mathrm{~N}_{5} \mathrm{O}(\%)$ : C 47.46, H 3.89, N 39.53, found: C 47.52, H 3.94, N 39.42.

\subsection{Synthesis of nanoMIP by ICAR-ATRP}

$\mathrm{Fe}_{3} \mathrm{O}_{4}$ nanoparticles (50 $\mathrm{mg}$, average $d=10 \mathrm{~nm}$ ) were dispersed in $10 \mathrm{~mL}$ of $2 \% \mathrm{PVP}\left(M_{\mathrm{w}} 10000\right)$ solution, then $20 \mathrm{~mL}$ of Span 80 in cyclohexane $(50 \mathrm{mM})$ was added under vigorous stirring for
$1 \mathrm{~h}$. Afterwards, $0.8 \mathrm{~mL}$ of TEOS was added, followed by $20 \mathrm{~min}$ ultrasonication. In this step, a $\mathrm{Fe}_{3} \mathrm{O}_{4}$-Span80-TEOS miniemulsion was gradually formed. This miniemulsion was allowed to gelate for $6-12 \mathrm{~h}$ at room temperature under stirring (1800 rpm), and $\mathrm{Fe}_{3} \mathrm{O}_{4} @ \mathrm{SiO}_{2}$ nanocomposites were obtained. The magnetic $\mathrm{Fe}_{3} \mathrm{O}_{4} @ \mathrm{SiO}_{2}$ nanocomposites were added into a $5 \%$ APTES ethanol solution ( $15 \mathrm{~mL}$ ), and stirred for $4 \mathrm{~h}$ to yield APTES-modified $\mathrm{Fe}_{3} \mathrm{O}_{4} @ \mathrm{SiO}_{2}$ nanoparticles. These nanoparticles were then collected by centrifugation and dispersed in $10 \mathrm{~mL}$ dry DCM. Afterwards, $0.5 \mathrm{~mL}$ of 2-bromoisobutyryl bromide (BiBB) was injected into the above solution under vigorous stirring for $4 \mathrm{~h}$, and the BiBB-modified $\mathrm{Fe}_{3} \mathrm{O}_{4} @ \mathrm{SiO}_{2}$ nanoparticles were obtained.

$\mathrm{Fe}_{3} \mathrm{O}_{4} @ \mathrm{SiO}_{2}-\mathrm{BiBB}$ nanoparticles (50 mg) were redispersed in $15 \mathrm{~mL}$ acetonitrile. To this suspension, a polymerization precursor in $10 \mathrm{~mL}$ methanol, consisting of the template BPDE16 merDNA probe ( 6 or $7,0.2 \mathrm{mmol}$ ), the functional monomer 1 (1.0 mmol) and $3(0.2 \mathrm{mmol})$, the crosslinker EDMA ( $5 \mathrm{mmol})$, the catalyst $\mathrm{CuBr}(20 \mu \mathrm{mol})$ and tris[2-(dimethylamino)ethyl] amine ( $\mathrm{Me}_{6}$ TREN, $\left.20 \mu \mathrm{mol}\right)$, and AIBN (16 mg) were added and vigorously stirred for $30 \mathrm{~min}$. Span 80 (2 mM, $2 \mathrm{~mL}$ in PBS) was added as the emulsifier. The resultant suspension was purged with nitrogen and then sealed, allowing the ATRP grafting to be carried out for $6-36 \mathrm{~h}$ at a temperature range of $25-80{ }^{\circ} \mathrm{C}$. The thickness of the grafted MIP layer could be tuned by controlling the reaction time. Finally, the template was removed from the nanoMIP by rinsing with phosphate buffer $(\mathrm{pH} 4.6)$ containing $10 \%$ methanol (volume proportion). NanoMIP could be transitorily dispersed in phosphate buffer containing 5-10\% ethanol prior to use. If not used immediately, it should be dispersed in ethanol and stored at $4{ }^{\circ} \mathrm{C}$ (not frozen), to avoid particle aggregation.

The non-imprinted polymer grafted $\mathrm{Fe}_{3} \mathrm{O}_{4} @ N I P$ nanocomposites (nanoNIP) were prepared by a similar synthetic procedure to the nanoMIP except that no template (BPDE-DNA adduct) was added in the polymerization. The prepared nanoMIP and nanoNIP were characterized by a S-3000N scanning electron microscope (SEM) and Hitachi H-7500 transmission electron microscope (TEM). The magnetization curves for the resultant nanomaterials were measured by a LDJ9600 vibrating sample magnetometer (VSM).

\subsection{LSCM fluorescent imaging of BPDE-DNA adducts}

DNA probes (BPDE-16merG16, BPDE-16merG9, BPDE16merG16-FAM) were prepared by mixing the corresponding adduct probe with 16merG16 (100 nM) and 16merG9 (100 nM) solutions to a certain final concentration, typically $1 \mathrm{nM}$ in this experiment. Similarly, the genomic DNA samples containing 18-1800 pM BPDE-DNA adducts were prepared by spiking different amounts of BPDE-gDNA standard solution to the unmodified genomic DNA $\left(100 \mu \mathrm{g} \mathrm{mL}^{-1}\right)$. The BPDE-gDNA standard was synthesized by the reaction of BPDE with genomic DNA isolated from cultured A549 cells. To calibrate the content of BPDE-DNA adducts in treated gDNA, one aliquot of genomic DNA was enzymatically digested into individual deoxynucleotides, and the BPDE-dG adduct was quantified by using stable 
isotope dilution LC-MS/MS analysis. ${ }^{45}$ The estimated total frequency of BPDE-DNA adducts in gDNA was 5.8 adducts per $10^{5}$ nucleotides, which was used as a BPDE-gDNA standard in this experiment.

The prepared DNA samples $(20 \mu \mathrm{L})$ were denatured at $95{ }^{\circ} \mathrm{C}$ for $10 \mathrm{~min}$, then $5 \mu \mathrm{L}$ of nanoMIP $\left(0.1 \mathrm{mg} \mathrm{mL}^{-1}\right)$ were added and incubated for $30 \mathrm{~min}$ with gentle swirling. The BPDE-DNA adducts were captured by the magnetic nanoMIP and isolated by a magnet, then washed with PBS twice. The unmodified DNA probes, undamaged ssDNA fragments and free BPDE could thus be removed. After that, the captured BPDE-DNA adducts were stained with fluorescent dye OliGreen (10 mM Tris-HCl buffer containing $1 \mathrm{mM}$ EDTA, $\mathrm{pH}$ 7.5). The collected magnetic nanoMIP were transferred onto a piece of coverglass and imaged using a laser scanning confocal microscope (LSCM).

Fluorescence images were acquired using a LSCM system consisting of a Leica DMI 6000B inverted microscope (objective, HCX PL APO CS; magnification/A.N., 63×/1.4-0.60 oil) equipped with a Leica TCS SP5 confocal scanning system. The fluorescence of DNA-OliGreen complexes was excited at $488 \mathrm{~nm}$ (argon ion laser, $4.5 \mathrm{~mW}$ ) and emission was detected at 500$550 \mathrm{~nm}$ by a photomultiplier tube (PMT). The gain of the PMT was set at $800 \mathrm{~V}$. The bright-field images were acquired at the same time with a PMT gain of $280 \mathrm{~V}$.

The image processing fluorescent dot counting was achieved by using ImageJ software, a public domain Java image processing program inspired by the National Institutes of Health. ${ }^{41,48}$ The fluorescent dots in images (8-bit image) were counted by setting a threshold at 20 pixels to exclude the background fluorescence. The fluorescent intensity of each dot was measured in a grey value range of 20-255. The total number of fluorescent dots were counted by using the 'Analyze Particles' function of the ImageJ software. Randomly counting at least 10 images gave the average number of fluorescent dots and standard deviation for each sample.

\section{Results and discussion}

Our fabrication strategy is illustrated in Scheme 1. The coreshell $\mathrm{Fe}_{3} \mathrm{O}_{4} @ M I P$ nanocomposite (nanoMIP) was prepared by initiators for continuous activator regeneration-atom transfer radical polymerization (ICAR-ATRP), using a BPDE-16merG16 DNA probe as the template. TEM images revealed that the diameters of the resultant nanoMIP were in the range of 120$170 \mathrm{~nm}$ (Fig. 1 and Fig. S1, ESI $\dagger$ ). Correspondingly, the shell thickness can be finely tuned by controlling the polymerization time (from 6 to $36 \mathrm{~h}$ ) during the ICAR-ATRP process, ranging from 10 to $40 \mathrm{~nm}$ (Fig. 1e). The synthesized nanoparticles exhibited typical superparamagnetic properties, with a decreased saturation magnetization with increasing shell thickness (Fig. 1f), $42.6 \mathrm{emu} \mathrm{g}^{-1}$ for a $20 \mathrm{~nm}$ shell (MIP20) and $17.4 \mathrm{emu} \mathrm{g}^{-1}$ for a $40 \mathrm{~nm}$ shell (MIP40). The core-shell nanoMIPs could be quickly isolated from the dispersed solution within a few seconds with a deposited Nd-Fe-B strong magnet (Fig. 1g).

Compared with the conventional ATRP applied for MIP fabrication, ${ }^{38,39}$ ICAR-ATRP uses a much lower concentration of a)

c)
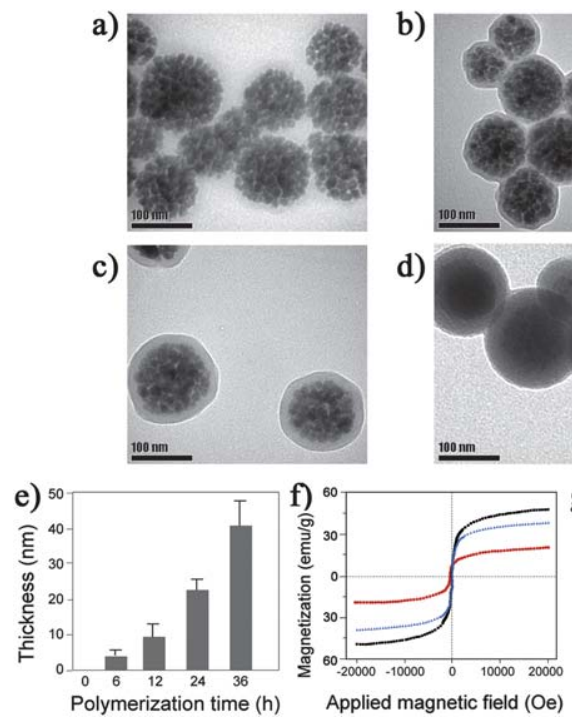

g)

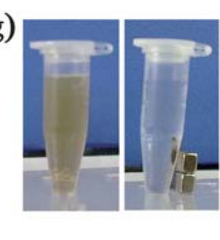

Fig. 1 TEM images of (a) $\mathrm{Fe}_{3} \mathrm{O}_{4} @ \mathrm{SiO}_{2}$, nanoMIP with a shell thickness of (b) $10 \mathrm{~nm}$ (MIP10), (c) $20 \mathrm{~nm}$ (MIP20) and (d) $40 \mathrm{~nm}$ (MIP40), (e) tuning the thickness of the MIP shell by applying different polymerization times $(0-36 \mathrm{~h})$ during the ATRP fabrication, (f) the magnetization curves of $\mathrm{Fe}_{3} \mathrm{O}_{4} @ \mathrm{SiO}_{2}$ nanoparticles (black), nanoMIP with a shell thickness of $20 \mathrm{~nm}$ (blue) and $40 \mathrm{~nm}$ (red), and (g) collection of the nanoMIP from the dispersed solution by a NdFeB magnet. The scale bars in (a)-(d) are $100 \mathrm{~nm}$.

metal catalyst $(\mathrm{CuBr})$, and thus greatly benefits the specificity of the binding sites towards the target molecules. $\mathrm{Cu}^{2+}$ residues, the oxidative product of $\mathrm{CuBr}$ produced in the ATRP reaction, were detected by inductively coupled plasma mass spectrometry (ICP-MS). The results show that less than $0.0023 \mu \mathrm{mol} \mathrm{g}^{-1}$ of $\mathrm{Cu}^{2+}$ remains in the prepared nanoMIP. In this case, the nonspecific adsorption is actually small, such that it has no obvious influence on the DNA-adduct detection in further studies.

The nanoscaled construction of nanoMIP ensured good site accessibility which enables a fast mass transfer. Fig. 2a shows the binding kinetic profile of BPDE-16merG16 on the MIP nanocomposites, exhibiting a fast target uptake with significant specific binding after $5 \mathrm{~min}$ and a saturation time within $15 \mathrm{~min}$. This implies that the nm-sized MIPs have a favorable effect on mass transfer of the target entering into the recognition sites. It seemed that MIPs with smaller thickness showed better accessibility towards the target molecules, and this would greatly benefit a fast binding process. Although most of the binding sites are still in the bulk of the MIP shell, if the MIP shell is sufficiently thin, the template can be extracted completely from the imprint sites, and similarly, the template can also reach the imprint sites easily and quickly during the rebinding step. By virtue of these merits, nanoMIP could be applied as a plastic antibody for fast binding and rapid screening of BPDE-ssDNA adducts in DNA samples.

\subsection{Selectivity of nanoMIP}

The selectivity factor $(S)$, which describes the specific recognition ability of $\mathrm{Fe}_{3} \mathrm{O}_{4} @$ MIP against BPDE-DNA adducts, can be 


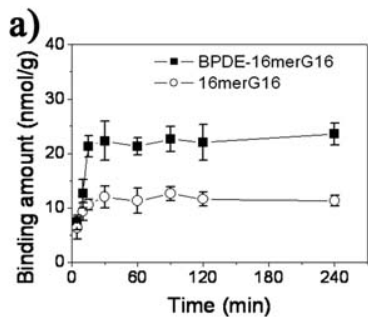

b)

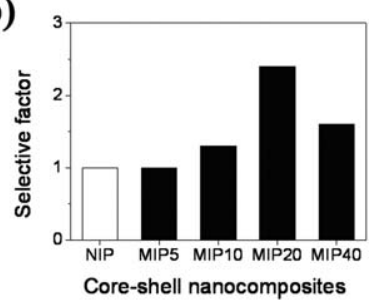

c)

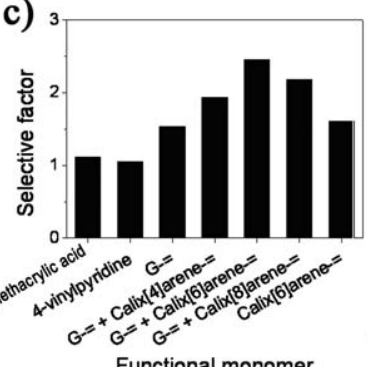

Functional monomer

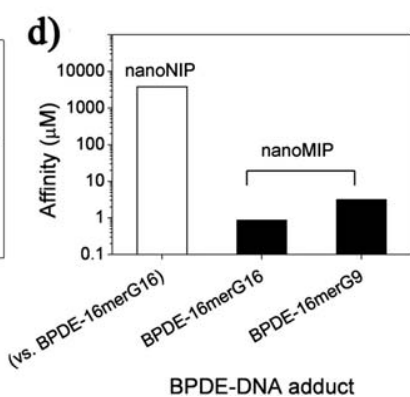

BPDE-DNA adduct
Fig. 2 (a) Binding kinetic profiles of BPDE-16merG16 ( $\boldsymbol{\square})$ and 16 merG16 (O) on nanoMIP20 ( $C=1.0 \mu \mathrm{M})$, (b) the relationship between selective factor and the thickness of the MIP shell, (c) the selection of functional monomers for nanoMIP fabrication, and (d) the affinity of nanoMIP and nanoNIP against the BPDE-DNA adducts.

calculated by comparing the partition coefficient $(K)$ of the nanoMIP with that of the nanoNIP (eqn (1) and eqn (2)). ${ }^{24,33}$

$$
\begin{gathered}
K=\frac{\left(C_{0}-C_{\mathrm{e}}\right) w_{\mathrm{s}}}{C_{\mathrm{e}} w_{\mathrm{n}}} \\
S=\frac{K(\text { nanoMIP })}{K(\text { nanoNIP })}
\end{gathered}
$$

where $C_{0}$ is the initial concentration of BPDE-DNA solution, $C_{\mathrm{e}}$ the equilibrium concentration of BPDE-DNA solution (which can be quantitatively determined by HPLC analysis), $w_{\mathrm{s}}$ the mass of BPDE-DNA solution, and $w_{\mathrm{n}}$ the mass of nanocomposites.

Interestingly, we found that the thickness of the nanoMIP shell affects its recognition ability in a thickness-dependent manner (Fig. 2b). MIP with a shell thickness of $20 \mathrm{~nm}$ (MIP20) exhibited a higher selective factor $(S=2.4)$ than those of $10 \mathrm{~nm}$ (MIP10, $S=1.3$ ) and $40 \mathrm{~nm}$ (MIP40, $S=1.6$ ), implying the geometry of the MIP shell has a profound effect on the recognition. MIP layer less than $5 \mathrm{~nm}$ (MIP5) showed no imprinting effect $(S=1.0)$. This is more likely because 16 merG16 has a molecular size comparable to $5 \mathrm{~nm}$ (given that the intermolecular distance in bases is $0.34 \mathrm{~nm}$ ) and few effective recognition sites were generated during the MIP synthesis.

Functional monomers influence the selectivity of nanoMIPs. NanoMIPs made with methacrylic acid (MAA) and 4-vinylpyridine (4-VP) gave low selective factors between 1.04 and 1.16 (Fig. 2c), implying those conventional functional monomers can not fulfill the requirements of synthesis of high-selectivity nanoMIPs. More potent functional monomers that can give higher selectivity are thus required. As for the BPDE-DNA adduct, the ideal functional monomer candidates should be able to specifically bind to the bases (A, T, C, G) and the modified moieties (herein BPDE) in DNA chains. For this purpose, $\mathrm{G}-=(\mathbf{1})$ and allyl-armed calix $[n]$ arene derivatives $(\mathbf{2}, \mathbf{3}$, 4) were synthesized (Scheme 2 ). We chose $\mathrm{G}-=$ as the functional monomer because the allylation of guanine at the N-9 position is easy to implement, where it does not interfere with the formation of triple hydrogen bonds with cytosine in the ssDNA chain. In addition, the allyl-armed calix $[n]$ arene $(2,3,4)$ acts as a $\pi$-acceptor which can interact with the BPDE moiety ( $\pi$-donor) by $\pi-\pi$ inclusion. It can be seen from Fig. $2 \mathrm{c}$ that the selectivity of nanoMIPs ( $S$ from 1.9 to 2.4 ) prepared with the combination of monomers $\mathrm{G}-=$ and calix $[n]$ arene- $=$ is relatively higher than that of nanoMIPs made with $\mathrm{G}-=(S=1.5)$ or calix[6]arene- $=(S=1.6)$ individually.

The specificity of calix[ $n]$ arene monomer towards the BPDE moiety could be modulated by tuning the number of phenol units $(n)$ in the molecular structures, and the cavity size thereof. The combination of $\mathbf{1}(\mathrm{G}-=)$ and $\mathbf{3}$ (calix[6]arene-=) exhibits the highest selectivity against the DNA adduct probes (Fig. 2c). This finding appears to conform with the cavity sizes of the allylarmed calix $[n]$ arenes and the molecular size of BPDE. ${ }^{7}$ The diameters of the allyl-armed calix[n] arene are 3.0, 7.6, 11.7 A for calix[4]arene, calix[6]arene and calix[8]arene with a depth of roughly $3 \AA^{49}$ The estimated size of BPDE is approximately $8.8 \AA$, which is too large to be included into calix[4] arene, but can fit snugly into the $7.8 \AA$ cavity of calix[6]arene. ${ }^{50}$ Allyl-armed calix[8]arene (4) should be able to accommodate one more stacked BPDE molecule, but in such a case, steric hindrance might occur, considering that the major groove of DNA is $1.2 \mathrm{~nm}$ wide and $0.85 \mathrm{~nm}$ deep. In this experiment, stoichiometrically mixed $\mathrm{G}-=$ and calix $[n]$ arene- $=$ monomers were employed in the nanoMIP fabrication. In contrast to the affinity $\left(K_{\mathrm{D}}\right.$ 86-225 $\left.\mu \mathrm{M}\right)$ generated with the conventional functional monomers MAA and 4-VP (Fig. S2, ESI $\dagger$ ), the cooperation of the new monomers provided at least 100 -fold enhanced affinity $\left(K_{\mathrm{D}}\right.$ $880 \mathrm{nM})$. We attribute this high affinity to the cooperation of base-pairing (multiple hydrogen bonding) and $\pi-\pi$ inclusion interactions generated between the designed monomers and the BPDE-DNA adduct.

\subsection{Affinity of nanoMIP}

The binding affinity of the nanoMIP antibody was investigated by a rebinding assay. Adsorption isotherms of BPDE-16merG16 and BPDE-16merG9 were depicted in Fig. 3a. Data from rebinding assays were further processed with the well-known Scatchard plot (eqn (3)). ${ }^{33,51-53}$

$$
\frac{Q}{C_{\mathrm{e}}}=\frac{Q_{\max }-Q}{K_{\mathrm{D}}}
$$

where $Q$ is the amount of BPDE-DNA adduct bound to nanoMIP, $Q_{\max }$ the apparent maximum number of binding sites, and $C_{\mathrm{e}}$ the free concentration of BPDE-DNA adduct at equilibrium. The binding affinity of the nanoMIP against the BPDE-DNA adduct is represented by the equilibrium dissociation constant $\left(K_{\mathrm{D}}\right)$.

The high affinity for nanoMIP against the probe $\mathbf{6}$ was achieved by Scatchard analysis at low target concentration levels 
a)

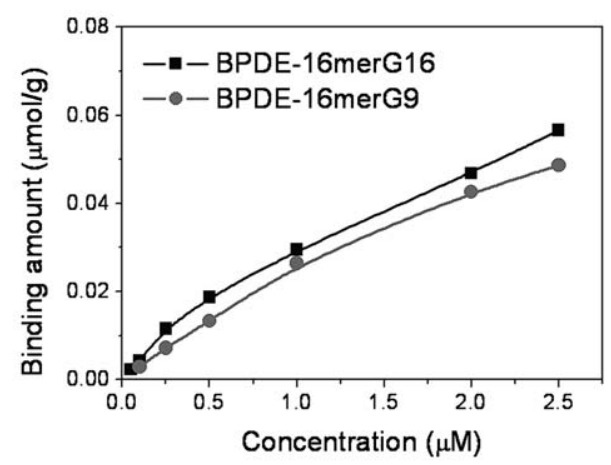

b)

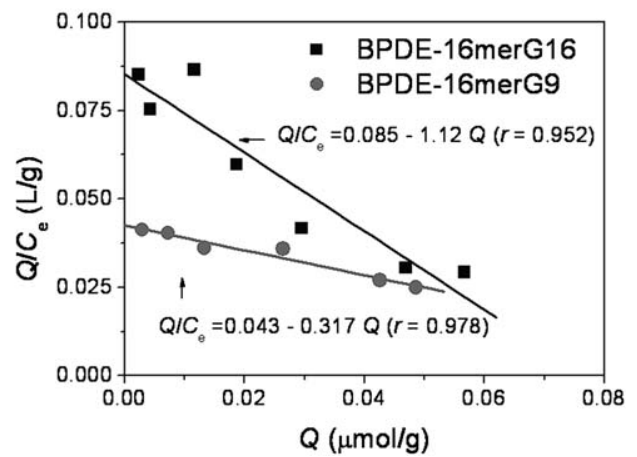

Fig. 3 (a) Adsorption isotherms of BPDE-16merG16 (square) and BPDE16 merG9 (circle) on nanoMIP. The concentration range is $0.05-2.5 \mu \mathrm{M}$ for BPDE16merG16, and 0.1-2.5 $\mu \mathrm{M}$ for BPDE-16merG9, respectively. (b) Scatchard plot for BPDE-16merG16 (square) and BPDE-16merG9 (circle) on the prepared nanoMIP. The affinity of nanoMIP against the corresponding probes can be calculated from the regression equations generated by Scatchard plotting. NanoMIP shows the highest affinity $K_{\mathrm{D}}$ of $880 \mathrm{nM}$ against BPDE-16merG16 and 3.16 $\mu \mathrm{M}$ against BPDE-16merG9.

(nM), assisted by HPLC-fluorescent detection. The Scatchard plot for nanoMIP shows only one straight line in the linear region (Fig. 3b). In this case, a precise plot curve could be obtained in the high-affinity region, at higher $Q / C_{\mathrm{e}}$ versus lower $Q$ values, providing micromolar and even nanomolar equilibrium dissociation coefficients. From the slope and intercept of the Scatchard plot, $K_{\mathrm{D}}$ and $Q_{\max }$ of the binding sites could be calculated. NanoMIP showed the highest affinity $K_{\mathrm{D}} 880 \mathrm{nM}$ against BPDE-16merG16 (probe 6) and 3.16 $\mu \mathrm{M}$ against BPDE16merG9 (probe 7) (Fig. 2d). Accordingly, the apparent maximum number is $0.076 \mu \mathrm{mol} \mathrm{g}^{-1}$ nanoMIP for BPDE16 merG16 and $0.134 \mu \mathrm{mol} \mathrm{g}^{-1}$ nanoMIP for BPDE-16merG9. This is probably because BPDE-16merG9, in which the BPDE moiety is on the middle G-9 site, has an extra steric hindrance effect towards the binding sites templated by probe 6 .

A cytosine-abundant BPDE-22merDNA probe 8 showed slightly lower affinity $\left(K_{\mathrm{D}} 2.4 \mu \mathrm{M}\right)$ than probe $6\left(K_{\mathrm{D}} 880 \mathrm{nM}\right)$ and comparable to that of probe $7\left(K_{\mathrm{D}} 3.4 \mu \mathrm{M}\right)$, indicating that the sequence and length of the ssDNA probes may influence the binding affinity. If this is the case, genomic DNA isolated from A549 cells, which are generally large in size $(20-80 \mathrm{~kb})$ in this experiment, would make the specific binding process more difficult. Fortunately, however, we found that the affinity of
nanoMIP $\left(K_{\mathrm{D}} 76 \pm 54 \mu \mathrm{M}\right)$ is by far good enough for the specific binding of BPDE-DNA adducts in genomic DNA, as compared with that of nonspecific nanoNIP $\left(K_{\mathrm{D}} \sim 3800 \mu \mathrm{M}\right)$.

\subsection{LSCM fluorescent imaging of BPDE-ssDNA adducts}

Based on the high specificity, it is feasible to apply this nanoMIP to the fluorescent imaging of BPDE-SSDNA probes by using a laser scanning confocal microscope (LSCM).

We first tested two BPDE modified ssDNA probes, BPDE16merG16 (1 nM) and BPDE-16merG16-FAM (1 nM), which was mixed with an excess of unmodified 16merG16 and 16merG9 (100 nM). Fig. 4 shows the representative LSCM images of BPDE-SSDNA probes captured by the nanoMIP. Numerous green fluorescent dots could be observed in the pictures in which both nanoMIP and BPDE-DNA adducts are present. By contrast, few or no fluorescent dots could be observed for the nanoNIP (the non-imprinted polymer). The captured BPDE16merG16 and BPDE-16merG16-FAM were also identified by matrix assisted laser desorption/ionization time-of-flight mass spectrometry. The presence of the protonated molecular ion $\left[(\mathrm{M}+\mathrm{H})^{+}\right]$at $m / z 5102.533$ (BPDE-16merG16) and $m / z 5640.371$ (BPDE-16merG16-FAM) confirmed the remarkable specificity of nanoMIP (Fig. 5).

It is worth noting that the small amount of BPDE binding to nanoMIP does not interfere with the BPDE-ssDNA detection. In this experiment, the captured BPDE-ssDNA fragments are stained with OliGreen and followed by LSCM imaging. The fluorescence of BPDE-ssDNA/OliGreen complexes is excited at $\lambda_{\mathrm{ex}}=488 \mathrm{~nm}$ and emission is detected at $\lambda_{\mathrm{em}}=500-550 \mathrm{~nm}$ by photomultiplier tube. Under these conditions, green dots of BPDE-ssDNA/OliGreen complexes can be observed, but no fluorescent dots of BPDE (typically $\lambda_{\mathrm{ex}}=293 \mathrm{~nm}, \lambda_{\mathrm{em}}=405 \mathrm{~nm}$ ) can be observed in LSCM images. Meanwhile, we also found that the background signals caused by nonspecific binding of

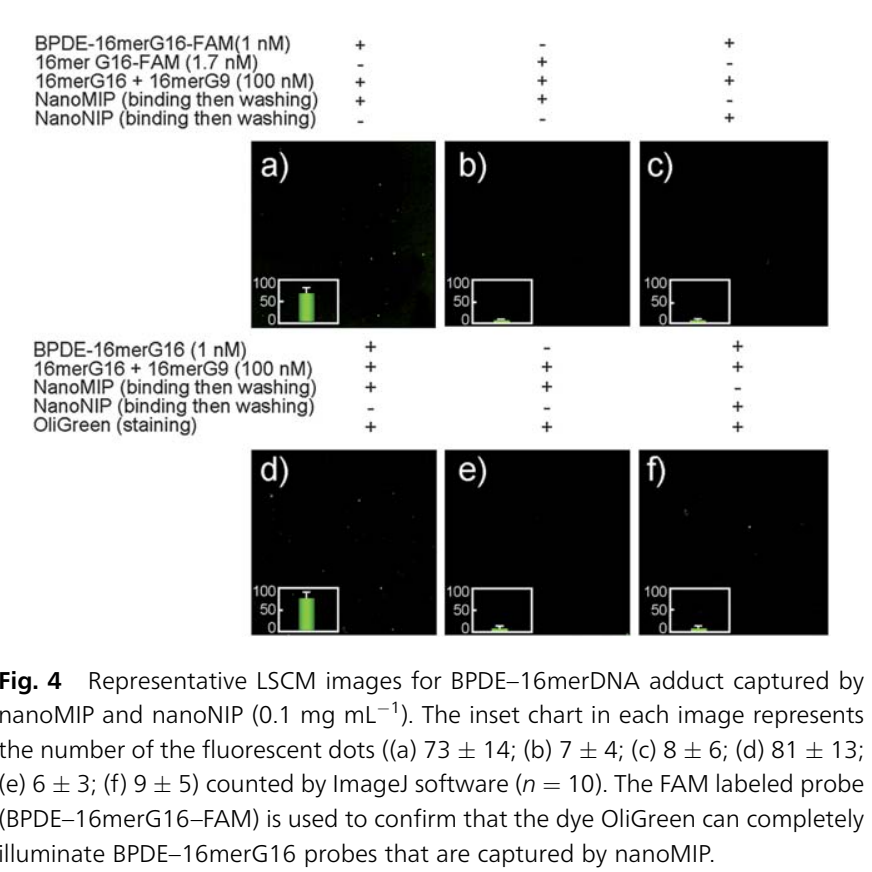


a)

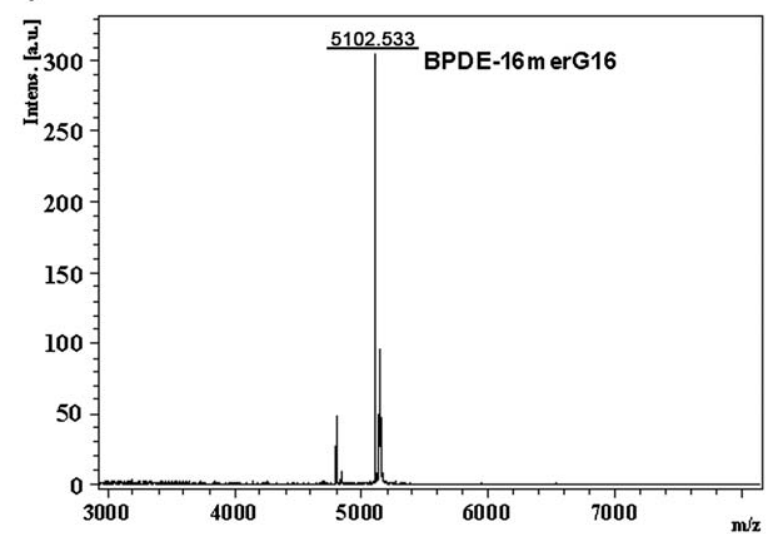

b)

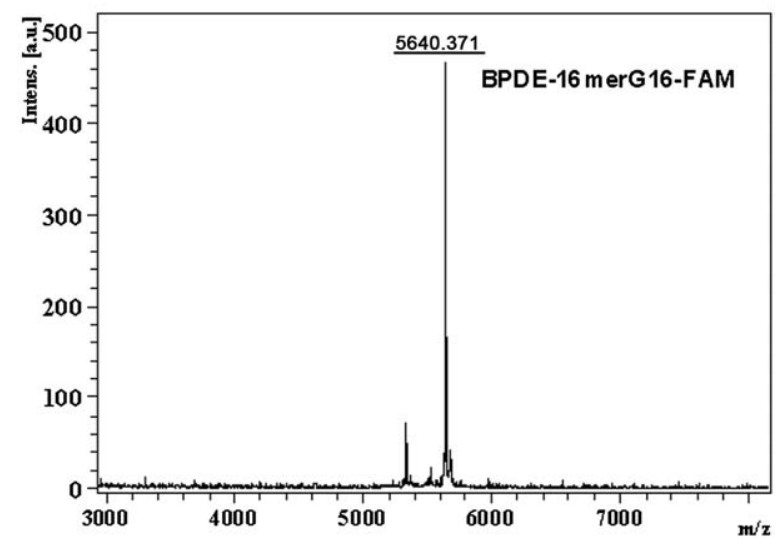

Fig. 5 MALDI-TOF MS analysis of (a) the captured BPDE-16merG16 and (b) BPDE-16merG16-FAM by nanoMIP.

OliGreen dye onto the nanoMIP could be effectively quenched, greatly reducing the background interferences thereby enhancing the detection sensitivity. ${ }^{41}$

\subsection{Fluorescently imaged particle counting immunoassay of} BPDE-ssDNA adducts in genomic DNA from cancer cells

We then applied this artificial antibody to fluorescent imaging of BPDE-DNA adducts in genomic DNA isolated from human lung carcinoma A549 cells. The gDNA samples were prepared according to our previous work, ${ }^{45}$ in which the isolated gDNA was melted to single strand DNA fragments and spiked with a certain amount of BPDE-gDNA precursor. The BPDE-adducted DNA fragments can be specifically captured by this plastic antibody by applying an external magnetic field. By taking advantage of this antibody-mimicking behavior, we further developed a fluorescently imaged particle counting immunoassay (FIPCIA) method for ultrasensitive detection of BPDEDNA adducts in genomic DNA from A549 cells.

As clearly shown in the fluorescent images (Fig. 6a), a number of green fluorescent dots can be observed for the gDNA samples (18-1800 pM). The long chain gDNA can accommodate more OliGreen molecules than short chain BPDE-DNA probes, hence producing brighter fluorescent signals and leading to higher quality images. The multiple labeling of captured DNA greatly brightens the particle, allowing for particle counting and greatly enhancing the detection sensitivity.

The LSCM images were then processed by ImageJ software, by which the number of the fluorescent dots could be counted. We found that the number of fluorescent dots in LSCM images increases with the increase of BPDE-DNA concentration in gDNA samples, while the nanoMIP in the bright-field image is generally equivalent $\left(0.1 \mathrm{mg} \mathrm{mL}^{-1}\right)$ for all DNA samples. Plotting the number of fluorescent dots versus the concentration of BPDE-DNA adducts reveals a double logarithmic correlation (Fig. 6b). The linearity could be evaluated based on the correlation between the logarithm of the dot number and the
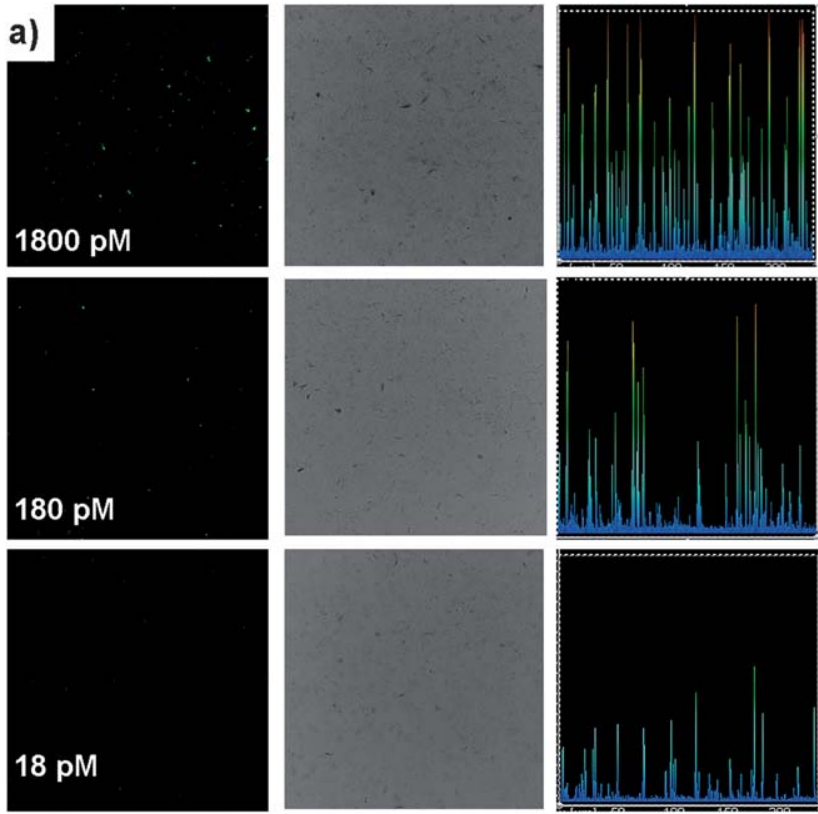

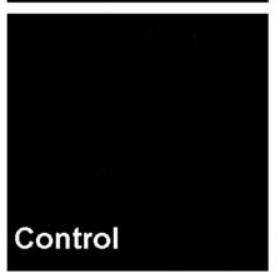

Fluorescent images

b)

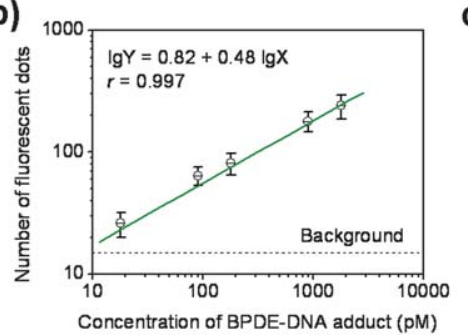

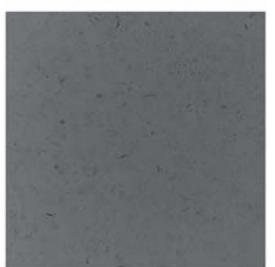

Bright-field images

c)

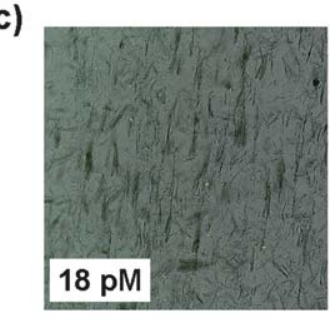

Fig. 6 (a) Representative fluorescent, bright-field and side-view images for detection of BPDE-DNA adducts by using nanoMIP $\left(0.1 \mathrm{mg} \mathrm{mL}^{-1}\right)$, (b) the linear relationship between the number of fluorescent dots and the concentration of BPDE-DNA adduct, and (c) the overlay image for detection of BPDE-DNA adducts (18 pM) by using $10 \times$ nanoMIP $\left(1.0 \mathrm{mg} \mathrm{mL}^{-1}\right)$. DNA samples (18-1800 pM) were prepared by spiking the untreated genomic DNA $\left(100 \mu \mathrm{g} \mathrm{mL}^{-1}\right)$ with the BPDEgDNA precursor. 
logarithm of adduct concentration. Thus, we could examine BPDE-DNA adducts as low as 18 pM by counting the number of fluorescent dots even in the presence of ten million times more nucleotides in the untreated gDNA. In addition, increasing nanoMIP to a 10 -fold concentration level $\left(1.0 \mathrm{mg} \mathrm{mL} \mathrm{mL}^{-1}\right)$, the nanoparticles were partly aggregated, but the number of fluorescent dots did not obviously increase by this aggregation (Fig. 6c). At the lower limit of quantification, $18 \mathrm{pM}$, the number of fluorescent dots for adducts $(25 \pm 6, n=10)$ can be easily differentiated from that of the negative control $(11 \pm 4, n=10)$. This implies the quantification of DNA adducts by LSCM imaging is independent on the nanoMIP concentration and insusceptible to their aggregation.

This plastic antibody-based FIPCIA technology can also provide advantages over natural antibody-based immunoassays. Firstly, nanoMIPs based on copolymer of ethylene glycol dimethacrylate and $\mathrm{G}-=$, calix $[n]$ arene- $=$ monomers are negatively charged, leading to less ssDNA molecules bound to a particle and emission of a weaker fluorescence signal. In natural antibody based immunoassays, the total fluorescence intensity is estimated rather than determined by counting particles for quantification, in which nonspecific binding may contribute to the total fluorescence signal and reduce the detection accuracy. Secondly, compared with biological antibodies, imprinted polymers have higher physical robustness, strength, resistance to elevated temperature and pressure and inertness towards acids, bases, metal ions and organic solvents. By means of conducting more rigorous washing steps with acids, bases and organic solvents, various nonspecific adsorptions on the surface of nanoMIP could be drastically removed. Finally, they are also less expensive to synthesize and the storage life of the polymers can be very long, maintaining their recognition capacity also for several years at room temperature.

\section{Conclusions}

In summary, we have fabricated a magnetic nanoMIP for recognition of BPDE-ssDNA adducts with high affinity and high specificity. Enhanced binding affinity ( $880 \mathrm{nM})$ of nanoMIP was achieved by using two tailor-made functional monomers. The homogeneity of binding sites and the mass transfer properties were greatly improved by taking advantage of the well-defined nanostructure constructed by ICAR-ATRP. The synthetic nanoMIP was successfully used as a potent plastic antibody for sensitive screening of trace of BPDE-DNA adducts (18 pM) in human lung carcinoma A549 cells. This highly-sensitive detection of DNA lesions offers a promising alternative to immunogenic antibody-based immunoassays for genomics and DNA modification analysis.

\section{Acknowledgements}

This work was supported by the grants from the National Basic Research Program of China (no. 2010CB933502 and 2011CB936001) and the National Natural Science Foundation of China (no. 20805057, 21077129 and 21125523), and the special fund for public benefit from Ministry of Environmental Protection of China (201309045).

\section{Notes and references}

1 D. K. La and J. A. Swenberg, Mutat. Res., Rev. Genet. Toxicol., 1996, 365, 129.

2 M. C. Poirier, Environ. Health Perspect., 1997, 105(suppl. 4), 907.

3 R. C. Gupta and W. K. Lutz, Mutat. Res., Fundam. Mol. Mech. Mutagen., 1999, 424, 1.

4 M. F. Denissenko, A. Pao, M. Tang and G. P. Pfeifer, Science, 1996, 274, 430.

5 A. Rundle, Mutat. Res., Fundam. Mol. Mech. Mutagen., 2006, 600, 23.

6 K. Haiser, B. P. Fingerhut, K. Heil, A. Glas, T. T. Herzog, B. M. Pilles, W. J. Schreier, Wo. Zinth, R. de Vivie-Riedle and T. Carell, Angew. Chem., Int. Ed., 2012, 51, 408.

7 R. B. Everson, E. Randerath, R. M. Santella, R. C. Cefalo, T. A. Avitts and K. Rasnderath, Science, 1986, 231, 54.

8 T. J. Carnelley, S. Barker, H. Wang, W. G. Tan, M. Weinfeld and X. C. Le, Chem. Res. Toxicol., 2001, 14, 1513.

9 R. Singh and P. B. Farmer, Carcinogenesis, 2006, 27, 178.

10 R. M. Santella, Cancer Epidemiol., Biomarkers Prev., 1999, 8, 733.

11 J. Topinka, A. Milcova, H. Libalova, Z. Novakova, P. Rossner, I. Balascak and R. J. Sram, Mutat. Res., Fundam. Mol. Mech. Mutagen., 2009, 669, 13.

12 X. C. Le, J. Xing, J. Lee, S. A. Leadon and M. Weinfeld, Science, 1998, 280, 1066.

13 H. Wang, M. Lu, M. Weinfeld and X. C. Le, Anal. Chem., 2003, $75,247$.

14 Z. Wang, M. Lu, X. Wang, R. Yin, Y. Song, X. C. Le and H. Wang, Anal. Chem., 2009, 81, 10285.

15 M. Zeisig and L. Moller, Carcinogenesis, 1995, 16, 1.

16 W. A. Spencer, J. Singh and D. K. Orren, Chem. Res. Toxicol., 2009, 22, 8.

17 A. G. Zavala, T. Lancaster, J. D. Groopman, P. T. Strickland and S. Chandrasegaran, Nucleic Acids Res., 2000, 28, e24.

18 H. Dai, R. Zhao, B. Haug, S. M. Hemmingsen and W. Xiao, Chin. Sci. Bull., 2001, 46, 1024.

19 A. A. Haller and P. Sarnow, Proc. Natl. Acad. Sci. U. S. A., 1997, 94, 8521.

20 S. M. Rink, J. C. Shen and L. A. Loeb, Proc. Natl. Acad. Sci. U. S. A., 1998, 95, 11619.

21 Y. Miyachi, N. Shimizu, C. Ogino, H. Fukuda and A. Kondo, Bioorg. Med. Chem. Lett., 2009, 19, 3619.

22 K. Mosbach and O. Ramstrom, Bio/Technology, 1996, 14, 163. 23 L. Ye and K. Mosbach, Chem. Mater., 2008, 20, 859.

24 H. H. Yang, S. Q. Zhang, W. Yang, X. L. Chen, Z. X. Zhuang, J. G. Xu and X. R. Wang, J. Am. Chem. Soc., 2004, 126, 4054. 25 X. Wang, J. Dong, H. Ming and S. Ai, Analyst, 2013, 138, 1219. 26 H. Nishino, C. S. Huang and K. J. Shea, Angew. Chem., Int. Ed., 2006, 45, 2392.

27 A. Nematollahzadeh, W. Sun, C. S. A. Aureliano, D. Lutkemeyer, J. Stute, M. J. Abdekhodaie, A. Shojaei and B. Sellergren, Angew. Chem., Int. Ed., 2011, 50, 495. 
28 J. Yin, G. Yang and Y. Chen, J. Chromatogr., A, 2005, 1090, 68. 29 S. W. Zhang, J. Xing, L. S. Cai and C. Y. Wu, Anal. Bioanal. Chem., 2009, 395, 479.

30 A. Ersöz, S. E. Diltemiz, A. A. Ozcan, A. Denizli and R. Say, Biosens. Bioelectron., 2008, 24, 742.

31 D. Cai, L. Ren, H. Zhao, C. Xu, L. Zhang, Y. Yu, H. Wang, Y. Lan, M. F. Roberts, J. H. Chuang, M. J. Naughton, Z. Ren and T. C. Chiles, Nat. Nanotechnol., 2010, 5, 597.

32 Z. Zeng, Y. Hoshino, A. Rodriguez, H. Yoo and K. J. Shea, ACS Nano, 2010, 4, 199.

33 J. Yin, Y. Cui, G. Yang and H. Wang, Chem. Commun., 2010, 46, 7688.

34 K. Matyjaszewski, Science, 2011, 333, 1104.

35 X. Wei and S. M. Husson, Ind. Eng. Chem. Res., 2007, 46, 2117.

36 H. Wang, W. Zhou, X. Yin, Z. Zhuang, H. Yang and X. Wang, J. Am. Chem. Soc., 2006, 128, 15954.

37 T. Pintauer and K. Matyjaszewski, Chem. Soc. Rev., 2008, 37, 1087.

38 K. Matyjaszewski, W. Jakubowski, K. Min, W. Tang, J. Huang, W. A. Braunecker and N. V. Tsarevsky, Proc. Natl. Acad. Sci. U. S. A., 2006, 103, 15309.

39 C. Gualandi, C. D. Vo, M. L. Focarete, M. Scandola, A. Pollicino, G. Di Silvestro and N. Tirelli, Macromol. Rapid Commun., 2013, 34, 51.
40 S. L. Hockley, V. M. Arlt, G. Jahnke, A. Hartwig, I. Giddings and D. H. Phillips, Carcinogenesis, 2008, 29, 202.

41 Z. Wang, X. Wang, S. Liu, J. Yin and H. Wang, Anal. Chem., 2010, 82, 9901.

42 D. Konkolewicz, A. J. D. Magenau, S. E. Averick, A. Simakova, H. K. He and K. Matyjaszewski, Macromolecules, 2012, 45, 4461.

43 L. Zhang, J. Miao, Z. Cheng and X. Zhu, Macromol. Rapid Commun., 2010, 31, 275.

44 G. Wang, M. Lu and H. Wu, Polymer, 2012, 53, 1093.

45 F. Feng, X. Wang, H. Yuan and H. Wang, J. Chromatogr., B: Anal. Technol. Biomed. Life Sci., 2009, 877, 2104.

46 L. C. Groenen, B. H. M. Ruel, A. Casnati, W. Verboom, A. Pochini, R. Ungaro and D. N. Reinhoundt, Tetrahedron, 1991, 47, 8378.

47 C. D. Gutsche and L.-G. Lin, Tetrahedron, 1986, 42, 1633.

48 ImageJ, http://rsb.info.nih.gov/ij.

49 C. D. Gutsche, Calixarenes (Revisited), in Monographs in Supramolecular Chemistry, ed. J. F. Stoddart, Royal Society of Chemistry, London, 1998.

50 R. Woodberry, S. Ransom and F. M. Chen, Anal. Chem., 1988, 60, 2621.

51 N. Funaya and J. Haginaka, J. Chromatogr., A, 2012, 1248, 18. 52 Y. Liu, K. Hoshina and J. Haginaka, Talanta, 2010, 80, 1713. 53 J. Yin, Z. Meng, Y. Zhu, M. Song and H. Wang, Anal. Methods, 2011, 3, 173. 